\title{
Aderência de revestimentos em paredes de blocos cerâmicos com função estrutural
}

\author{
Adherence of ceramic tiles on structural ceramic block \\ masonry
}

\begin{abstract}
Jefferson Sidney Camacho
Valério Paz Dorneles

Guilherme Aris Parsekian

Alexsandro dos Santos Felipe

Resumo

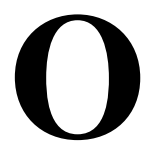

presente trabalho tem por objetivo verificar o comportamento mecânico dos revestimentos cerâmicos frente aos carregamentos na alvenaria estrutural. Neste estudo são apresentados os resultados experimentais e conclusões sobre o comportamento de paredes revestidas quando submetidas a carregamentos verticais crescentes até a ruptura. Os revestimentos foram fixados com argamassa colante industrial, aplicados em paredes de blocos cerâmicos com e sem emboço. Ao longo dos ensaios foram registrados todos os eventos considerados importantes, tais como deformações, início de fissuração, descolamento dos revestimentos, formas e cargas de rupturas. Dessa forma, foi possível quantificar a relação dos carregamentos presentes nas paredes com as fissurações e desprendimentos dos revestimentos cerâmicos, onde se pode verificar que os problemas patológicos ocorreram próximos aos limites de carregamento da estrutura, indicando que o sistema de revestimentos não sofreram relativas alterações visuais e mecânicas dentro do regime estrutural de utilização.
\end{abstract}

Jefferson Sidney Camacho Universidade Estadual Paulista Júlio de Mesquita Filho Itha Solteira - SP - Brasil

Valério Paz Dorneles Tecno Logys São Paulo - SP - Brasil

Guilherme Aris Parsekian Universidade Federal de São Carlos São Carlos - SP - Brasil

Alexsandro dos Santos Felipe Universidade Estadual Paulista Júlio de Mesquita Filho Itha Solteira - SP - Brasil

Recebido em 26/01/15 Aceito em 25/11/15

Palavras-chaves: Aderência. Alvenaria estrutural. Bloco cerâmico. Revestimento externo.

\section{Abstract}

The aim of this paper is to assess the mechanical behaviour of ceramic tiles on a structural masonry wall submitted to vertical loading. This study presents the results and conclusions of experiments carried out on ceramic block masonry walls coated with ceramic tiles and submitted to increasing vertical loads up to the system's complete failure. The ceramic tiling was applied on the walls using dry set mortars either directly on the blocks or on a plastering mortar layer. During the tests, all the important events, such as strains, onset cracks, tile detaching, rupture shape and load values, were registered. It was possible to determine the relationship between loads and the occurrence of cracks or tile detachment.

Cracking or detachment of ceramic tiles only occurred at load values close to each wall's failure load. That indicates that the tiles had good adherence to the wall up to loads much higher than those expected. This indicates that the rendering tyles did not have any visual or mechanical failures when they were on walls under service loads

Keywords: Adherence. Structural masonry. Ceramic block. External coating. 


\section{Introdução}

De modo significativo, a construção de edificações em que a função estrutural passa a ser desempenhada pelas paredes, chamada de sistemas de Alvenaria Estrutural, vem fazendo parte do cenário da construção civil brasileira. Se no passado esse sistema era executado em sua maioria com blocos de concreto, atualmente verifica-se também um expressivo uso de blocos cerâmicos com funções estruturais, principalmente nas regiões dos grandes centros urbanos.

Tornando-se cada vez mais usual o emprego de blocos cerâmicos para a montagem de paredes de vedação em sistemas estruturais reticulados, assim como ocorre nos blocos de concreto, aproveita-se também a mesma técnica de coordenação modular, permitindo a racionalização da execução de diversas etapas da construção. Como essas estruturas são projetadas com acentuada esbeltez, as deformações decorrentes acabam implicando na transferência de carregamentos para as paredes com o sistema de revestimentos cerâmicos que, a princípio, não são projetadas para tal.

Conforme Medeiros e Sabbatini (1999) e Lima (2003), um sistema de revestimento cerâmico é caracterizado como um grupo monolítico de camadas ligadas de maneira compacta ao substrato, seja este estrutural ou não. Destas camadas, a última que configura a fachada do edifício pode ser de placas cerâmicas devidamente colocadas por meio de argamassa colante e rejunte.

Segundo Sabbatini e Barros (1990), a presença de problemas patológicos caracterizados por fissuras ou pelo desprendimento de revestimentos é baseada numa morfologia de fratura típica de materiais frágeis. Cavalheiro e Muller (1991) e Collantes (1998) atribuem a isto os níveis de deformações impostas nas paredes ocasionando uma movimentação diferenciada entre alvenaria e o correspondente revestimento. A consequência, em termos de solução de obra, tem sido o emprego de técnicas que permitam um "desligamento" entre a parede e a estrutura propriamente dita.

A capacidade de absorver deformações varia entre os diferentes tipos de estruturas. Nas situações em que ocorre a ligação entre a alvenaria estrutural e o concreto armado, por exemplo, regiões comuns de desprendimentos são verificadas, como se pode observar na Figura 1 (as fotos são de autoria dos próprios autores deste trabalho).

Segundo Sichieri e Lima (1998), nos sistemas de alvenaria estrutural, uma maneira de minimizar as deformações relativas entre paredes e revestimentos seria a aplicação dos revestimentos após as paredes terem sido submetidas a determinados níveis de carregamento, minimizando as deformações relativas entre paredes e revestimentos. Contudo, é necessário conhecer todos os materiais empregados e a apropriação destes quanto ao tipo de uso.

Segundo Junginger (2014), diversas variáveis são responsáveis pelo bom ou mau desempenho dos revestimentos, e estas variáveis podem ser mais ou menos importantes para cada tipo de edificação e entorno de uma atmosfera que pode variar muito ao longo deste país de característica continental

Fenômenos correspondentes à variação térmica estudada por Feres (2004), que podem gerar problemas patológicos na placa cerâmica e no rejunte, não foram empregados neste trabalho, uma vez que precisariam de uma atmosfera apropriada e controlada para garantir a real troca de calor entre a estrutura e o ambiente externo. Outras manifestações patológicas decorrentes das variações climáticas que atuam de maneiras diferentes no sistema de revestimento poderiam melhor ser estudadas se houvesse especificações dos coeficientes de expansão térmica de cada elemento (argamassa, rejunte, placa cerâmica, etc.) por parte dos fabricantes.

Ribeiro (2006) entende que o uso de revestimentos cerâmicos nas fachadas de edifícios trazem vantagens estéticas, na manutenção e limpeza, como também em um potencial aumento da durabilidade dos elementos estruturais que antes estavam mais expostos ao ambiente externo. Boschi (2002) afirma que o uso destes revestimentos em fachadas de edifícios não é mais frequente devido à pouca especificação de alguns fabricantes quanto à finalidade de aplicação. Porém, para Bowman (2008), outros problemas patológicos são originados pela baixa qualificação profissional de uma grande parcela dos azulejistas.

Dentro desse contexto, o presente trabalho procura contribuir para o entendimento do comportamento dos revestimentos cerâmicos quando aplicados sobre paredes que estão sujeitas a níveis de tensões superiores aqueles causados simplesmente pelo seu peso próprio, verificando se em condições ideais de aplicação e execução dos revestimentos haveria manifestações patológicas na fase de utilização da edificação, consideravelmente abaixo do limite de ruptura. 
Figura 1 - Regiões mais comuns dos desprendimentos de emboço em ligações de alvenaria estrutural de blocos cerâmico e concreto armado

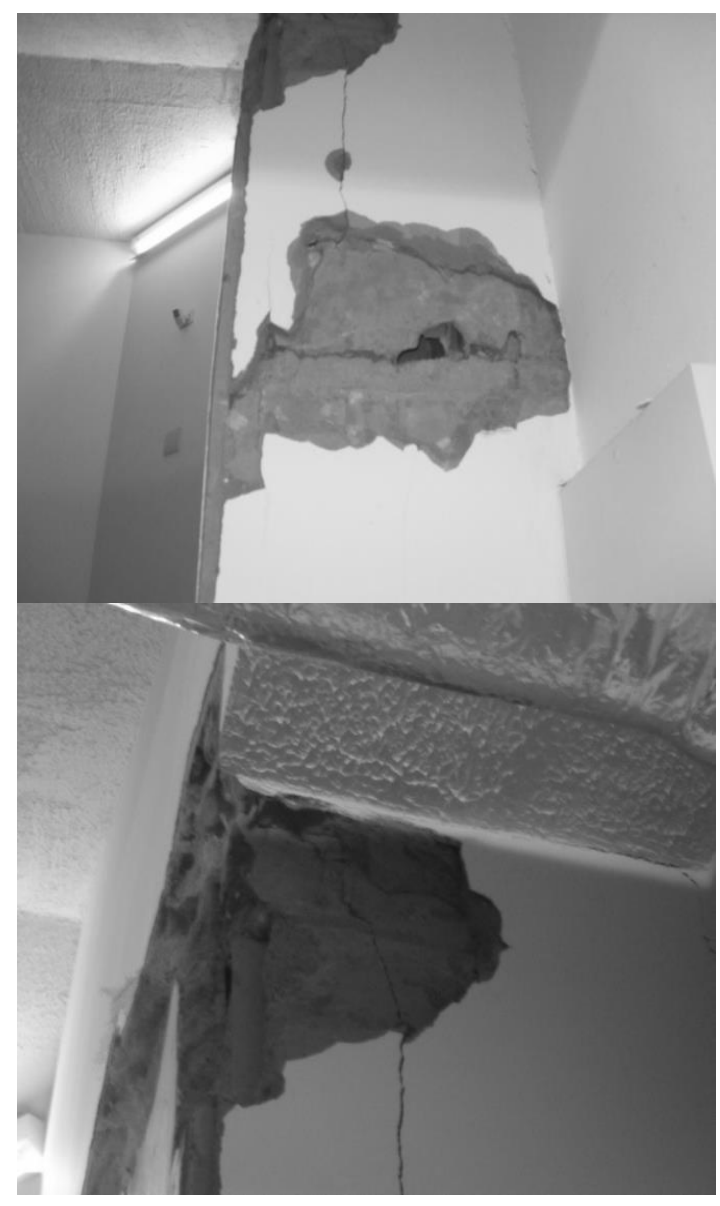

Materiais e métodos

\section{Argamassa de assentamento e emboço}

Seguindo o procedimento de preparo semelhante ao proposto por Romano et al. (2010), a argamassa de assentamento e emboço utilizada nas paredes foi a mista, composta por cimento, cal e areia, na respectiva proporção de 1:0,5:4, contendo areia do tipo grossa lavada, para assemelhar-se a uma obra convencional foi utilizada uma betoneira inclinada a $30^{\circ}$, conforme é mostrada na Figura 2. A espessura do emboço foi determinada de acordo com as prescrições normativas da NBR 13749 (ABNT, 2013).

De acordo com a NBR 15812-2 (ABNT, 2010), procurou-se adequar as condições ambientais do laboratório que atendesse satisfatoriamente a aplicação dos revestimentos cerâmicos nos pertinentes substratos (emboço ou bloco cerâmico).

A argamassa colante industrializada é de origem industrializada, composta de cimento Portland,

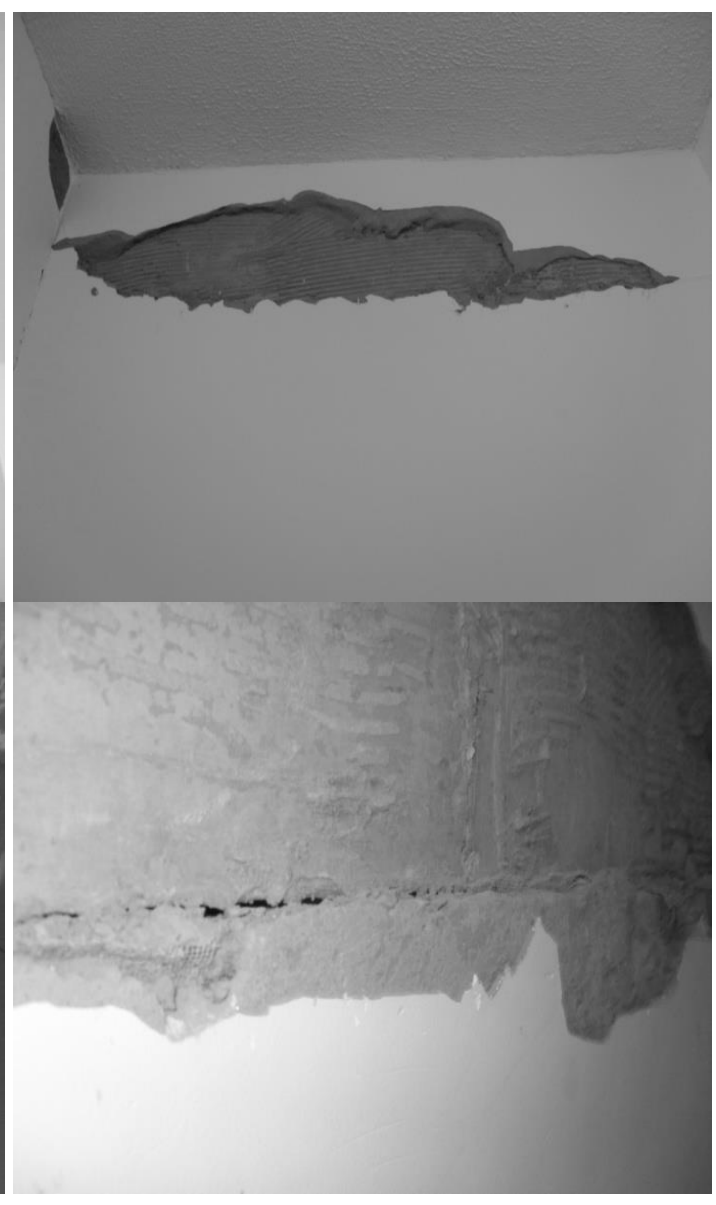

aditivos e agregados minerais, a argamassa colante industrializada é ensacada em estado seco e quando misturada com a água apresenta propriedades de aderência, viscosidade e plasticidade adequadas aos padrões normativos da NBR 14081-1 (ABNT, 2012) para o assentamento de placas cerâmicas de revestimento.

O modo de mistura da argamassa foi manual até obter uma consistência uniforme, depois se deixou descansar por 15 minutos antes da aplicação, o rejunte utilizado foi do tipo comum (flexível), comercialmente utilizado.

\section{Blocos}

Segundo Bortoluzzo (2000), os blocos são responsáveis pela capacidade de suporte dos carregamentos impostos sobre a estrutura, assim como, devem ser duráveis e com boa precisão dimensional, porém, expansões térmicas e retrações por secagem podem comprometer a aderência entre o bloco e o revestimento, ocasionando fissuras na interface com a 
argamassa. Os blocos vieram da produção regular de uma indústria cerâmica da cidade de Jundiaí.

Neste estudo e conforme as prescrições da NBR 15270-1 (ABNT, 2005a) foram utilizados blocos cerâmicos com dimensões de fabricação pertencentes à família $(14 \times 19 \times 39) \mathrm{cm}$, respectivamente a largura, altura e comprimento, conforme mostrado na Figura 3. Os ensaios de resistência à compressão dos blocos seguiram as prescrições normativas da NBR 15270-2 (2005b) e da NBR 15270-3 (2005c), essas informações estão apresentadas na Tabela 1 .

\section{Figura 2 - Esquema de produção da argamassa de emboço e assentamento}

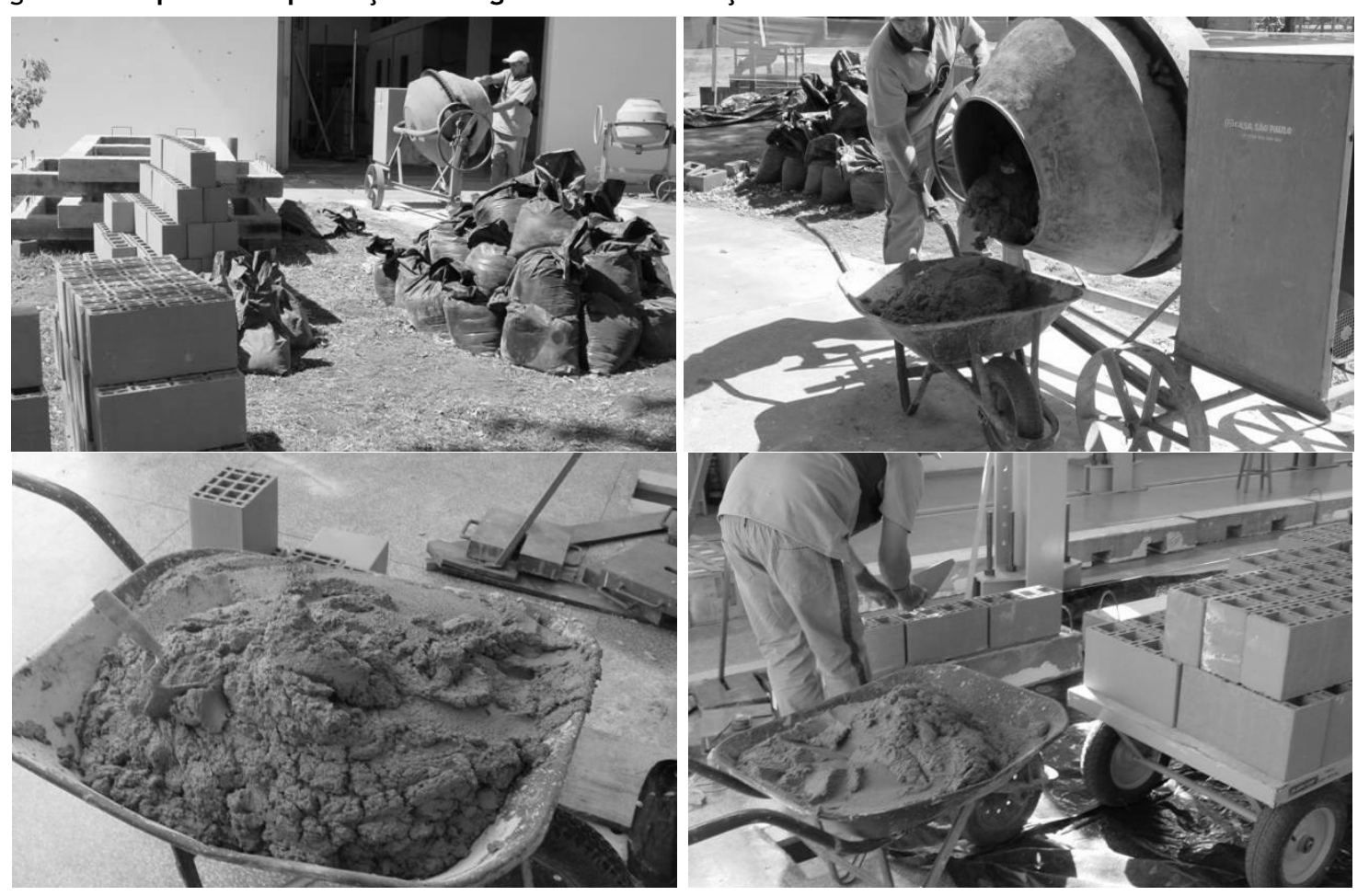

Figura 3 - Blocos cerâmicos usados no estudo

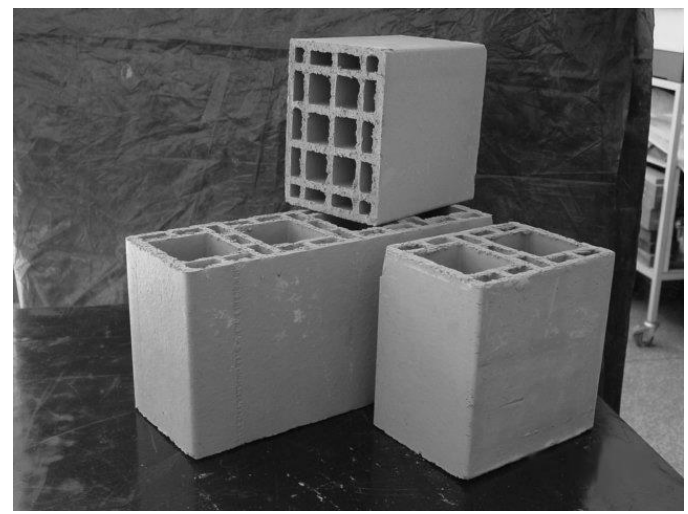

Tabela 1 - Resistência dos blocos cerâmicos

\begin{tabular}{c|c|c}
\hline Material & Carga (kN) & Tensão (MPa) \\
\hline & 530 & 9,52 \\
Bloco cerâmico inteiro & 595 & 10,68 \\
& 630 & 11,31 \\
& 426 & 7,65 \\
\hline Média & 545,25 & 9,79 \\
\hline Desvio padrão & 89,65 & 1,61 \\
\hline
\end{tabular}

112 Camacho, J. S.; Dorneles, V. P.; Parsekian, G. A.; Felipe, A. dos S. 


\section{Paredes}

Seguindo as orientações de execução de Cardoso et al. (2007), no desenvolvimento do programa experimental foram construídas seis paredes com dimensões $(120 \times 100) \mathrm{cm}$, todas executadas diante de uma criteriosa supervisão técnica sobre a mão de obra. Estas paredes foram assentadas sobre uma viga de concreto (base) para sua movimentação e sobre as mesmas foram colocadas vigas de reação de concreto com resistência à compressão característica $\left(\mathrm{f}_{\mathrm{ck}}\right)$ de $25 \mathrm{MPa}$, simulando uma situação semelhante ao que ocorre na obra, com dimensões $(20 \times 20 \times 120) \mathrm{cm}$, através das quais foram introduzidos os carregamentos de compressão nas paredes, conforme Figura 4. Todas as vigas utilizadas foram duplamente armadas.

Em três paredes foram executadas camadas de emboço em uma das faces (PCE-R) com 1,5 cm de espessura, espessura na qual está dentro da faixa recomendada por Lima (2003). Este emboço envolveu também a viga de reação, sobre o qual foram aplicadas as placas cerâmicas com argamassa colante conforme as prescrições da NBR 13755 (1996). Nas outras três paredes, o revestimento foi aplicado sem a presença do emboço (PCE), diretamente sobre os blocos cerâmicos, envolvendo a viga superior de concreto, também com argamassa colante.

Os ensaios foram realizados com carregamento a uma taxa constante de aproximadamente 0,05 $\mathrm{MPa} /$ segundo que conduziu as paredes até a ruptura, sendo registradas as deformações $(\varepsilon)$ através de dois transdutores de deslocamentos (relógios comparadores com precisão de 0,001 $\mathrm{mm})$ fixados em suas laterais na $4^{\circ}$ fiada de baixo para cima e ligados a um sistema de aquisição desenvolvido pelo programa Deasy Lab ${ }^{\mathrm{TM}}$.

A execução das paredes, emboço e a aplicação dos revestimentos foram realizados por mão de obra especializada e que atendesse as prescrições normativas a esse tipo de assentamento em obras reais, conforme Figuras 5, 6 e 7.

Os ensaios foram acompanhados de modo a possibilitar o registro de todos os eventos importantes, tais como a ocorrência de estalos internos e sua respectiva deformação $\left(\varepsilon_{d c}\right)$, surgimento de fissuras (nas duas faces, com e sem o revestimento), descolamento dos revestimentos e do emboço.

\section{Ensaios de compressão axial}

Para a realização dos ensaios de compressão axial, todos os corpos-de-prova foram capeados com uma fina camada de gesso, de modo a corrigir as imperfeições de assentamento e dos materiais, evitando assim que essas imperfeições pudessem ocasionar a concentração de tensões durante os ensaios de compressão, influenciando nos valores dos resultados obtidos.

As paredes de alvenaria foram ensaiadas em pórticos de reação, segundo as prescrições normativas da NBR 8949 (ABNT, 1985). Para as medidas das deformações foram utilizados dois relógios comparadores colados nas faces laterais, sendo todas as informações capturadas por um sistema de aquisição, conforme mostra a Figura 8.

Figura 4 - Blocos cerâmicos usados no estudo

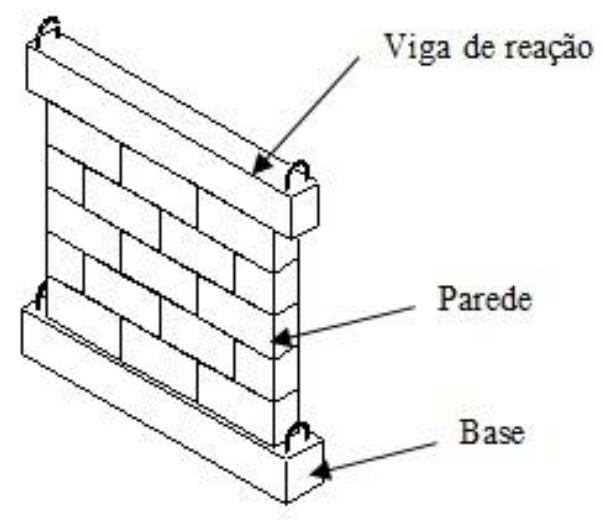


Figura 5 - Execução das paredes cerâmicas
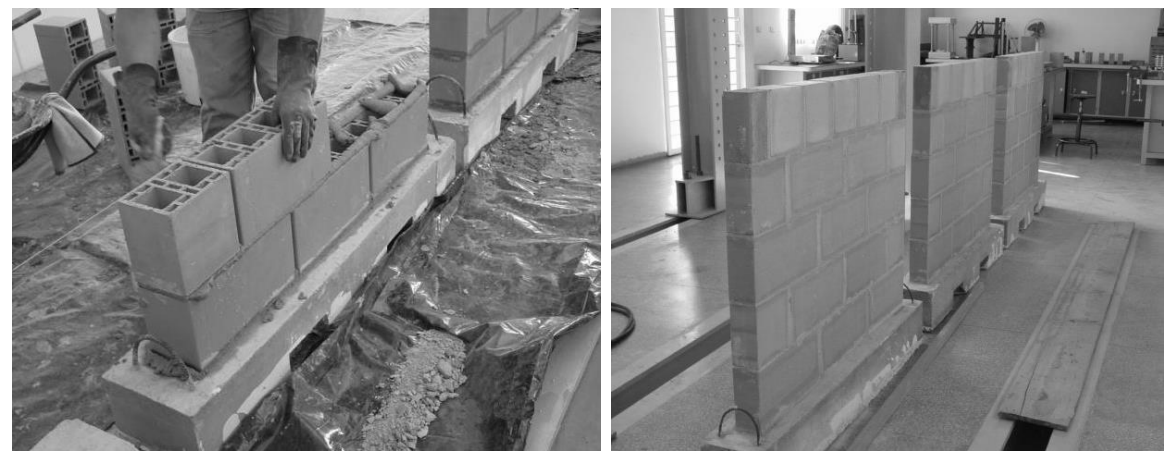

Figura 6 - Execução dos emboços das paredes cerâmicas
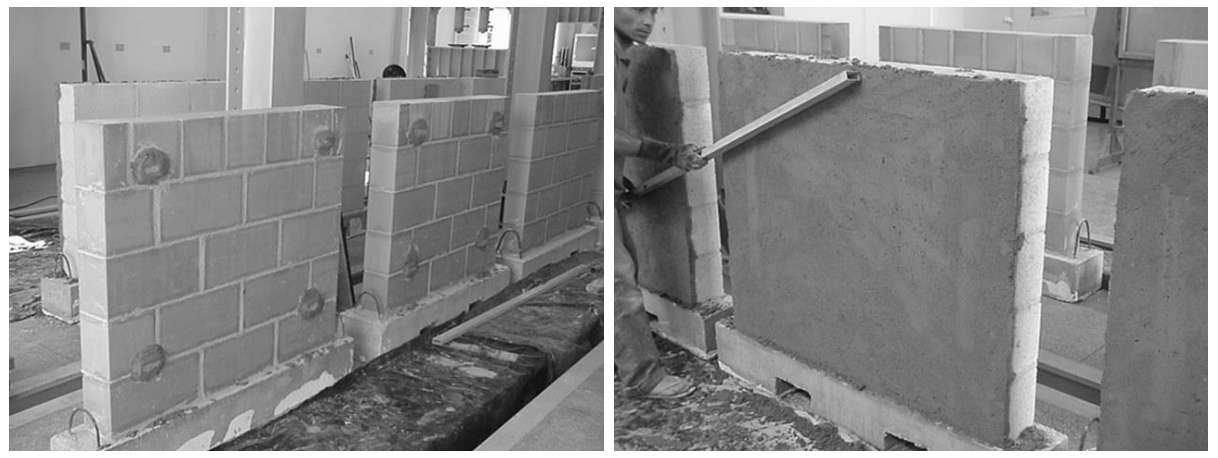

Figura 7 - Execução das vigas superiores (paredes com e sem emboço)
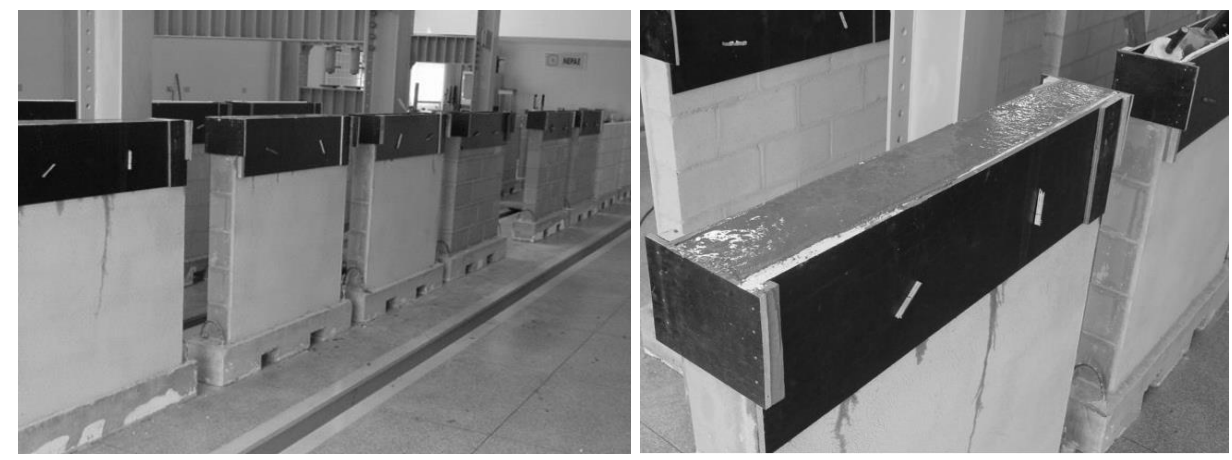

Figura 8 - Esquema de ensaios das paredes

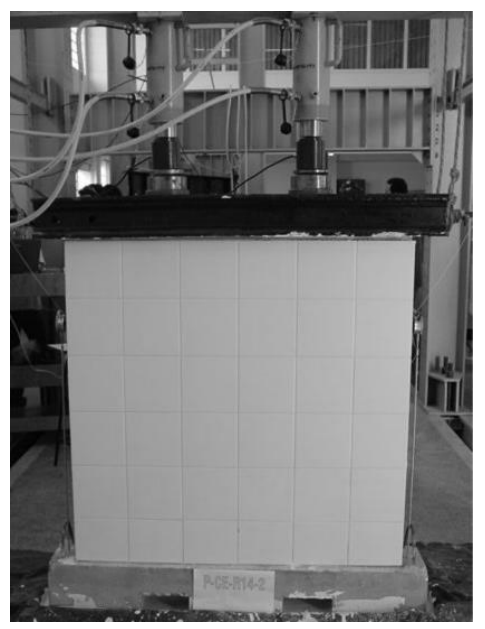

114 Camacho, J. S.; Dorneles, V. P.; Parsekian, G. A.; Felipe, A. dos S. 


\section{Resultados e análises}

Os resultados e eventos (carga registrada no surgimento do ruído interno (Pri), carga registrada no momento do descolamento (Pdc) e a carga de ruptura $(\mathrm{P})$ ) observados nos ensaios de compressão axial nas paredes cerâmicas estão apresentados nas Tabelas 2 e 3.

Nas Figuras 9 e 10 são apresentados os valores medidos nos ensaios das paredes e os eventos observados, tais como a produção de ruídos internos nas paredes (estalos) e o desprendimento dos revestimentos, associando a esses eventos as respectivas cargas, tensões e deformações atuantes nas paredes. Nas Figuras 11, 12 e 13 é possível visualizar as formas de ruptura das paredes.

Por meio da Figura 9 é possível verificar que os ruídos e desprendimentos do revestimento cerâmico ocorreram praticamente no instante da carga de ruptura nas paredes com emboço. Nas paredes sem o emboço nota-se também que o desprendimento ocorreu próximo ao limite estrutural da parede.
Os ruídos (estalos) internos percebidos nas paredes, indicando um possível desprendimento do revestimento em alguns pontos, ocorreram somente nas paredes sem emboço a uma carga média de $310 \mathrm{kN}$ que corresponde a aproximadamente $81 \%$ da carga média de ruptura dessas paredes. Apesar desse comportamento, é razoável supor que o risco de aparecimento de problemas patológicos no tipo de revestimento utilizado neste trabalho em função do carregamento da parede não é elevado, uma vez que, durante sua vida útil, é improvável que o carregamento atuante se aproxime tanto de seus valores últimos.

Para o caso das paredes com emboço, não foi percebido nenhum indício de desprendimento deste em relação à parede propriamente dita. Contudo, antes das proximidades da carga de ruptura, foi observada uma fissura significativa na região da viga superior de concreto, entre o emboço e a viga, sem se propagar para a região da alvenaria.

Tabela 2 - Eventos observados nos ensaios das paredes

\begin{tabular}{|c|c|c|c|c|}
\hline \multicolumn{2}{|c|}{ Parede } & $\begin{array}{c}\mathbf{P}_{\mathbf{r i}} \\
(\mathbf{K N})\end{array}$ & $\begin{array}{c}\mathbf{P}_{\mathrm{dc}} \\
(\mathbf{K N})\end{array}$ & $\begin{array}{c}\mathbf{P} \\
(\mathbf{K N})\end{array}$ \\
\hline \multirow{3}{*}{ PCE-R } & 1 & --- & 510 & 513 \\
\hline & 2 & ---- & 500 & 503 \\
\hline & 3 & ---- & 560 & 560 \\
\hline \multicolumn{2}{|c|}{ Média } & $\begin{array}{ll}--- \\
\end{array}$ & 523 & 525 \\
\hline \multicolumn{2}{|c|}{ Desvio padrão } & ---- & 32,15 & 30,44 \\
\hline \multirow{3}{*}{ PCE } & 1 & 360 & 385 & 385 \\
\hline & 2 & 279 & 350 & 365 \\
\hline & 3 & 290 & 355 & 395 \\
\hline \multicolumn{2}{|c|}{ Média } & 309,67 & 363,33 & 381,67 \\
\hline \multicolumn{2}{|c|}{ Desvio padrão } & 43,94 & 18,93 & 15,28 \\
\hline
\end{tabular}

Nota: Legenda:

PCE-R: Paredes com emboço; e

PCE: Paredes sem emboço.

Tabela 3 - Resultados dos ensaios das paredes

\begin{tabular}{|c|c|c|c|c|c|}
\hline \multicolumn{2}{|c|}{ Parede } & $\begin{array}{c}\mathbf{P}_{\mathbf{d c}} \\
(\mathbf{k N})\end{array}$ & $\begin{array}{c}\varepsilon_{(\mathrm{dc})} \\
(\mathrm{mm} / \mathbf{m m})\end{array}$ & $\frac{P}{(k N)}$ & $\begin{array}{c}\varepsilon \\
(\mathrm{mm} / \mathrm{mm})\end{array}$ \\
\hline \multirow{3}{*}{ PCE-R } & 1 & 510 & 0,0014 & 513 & 0,0015 \\
\hline & 2 & 500 & 0,0016 & 503 & 0,0016 \\
\hline & 3 & 560 & 0,0016 & 560 & 0,0016 \\
\hline \multicolumn{2}{|c|}{ Média } & 523,33 & 0,0014 & 525,33 & 0,0015 \\
\hline \multicolumn{2}{|c|}{ Desvio padrão } & 32,15 & 0,0014 & 30,44 & 0,0015 \\
\hline \multirow{3}{*}{ PCE } & 1 & 385 & 0,0016 & 385 & 0,0021 \\
\hline & 2 & 350 & 0,0024 & 365 & 0,0029 \\
\hline & 3 & 355 & 0,0017 & 395 & 0,0021 \\
\hline \multicolumn{2}{|c|}{ Média } & 363,33 & 0,0019 & 381,67 & 0,0024 \\
\hline \multicolumn{2}{|c|}{ Desvio padrão } & 18,93 & 0,0004 & 15,28 & 0,0005 \\
\hline
\end{tabular}


Figura 9 - Cargas correspondentes aos estalos, desprendimentos dos revestimentos e ruptura da parede

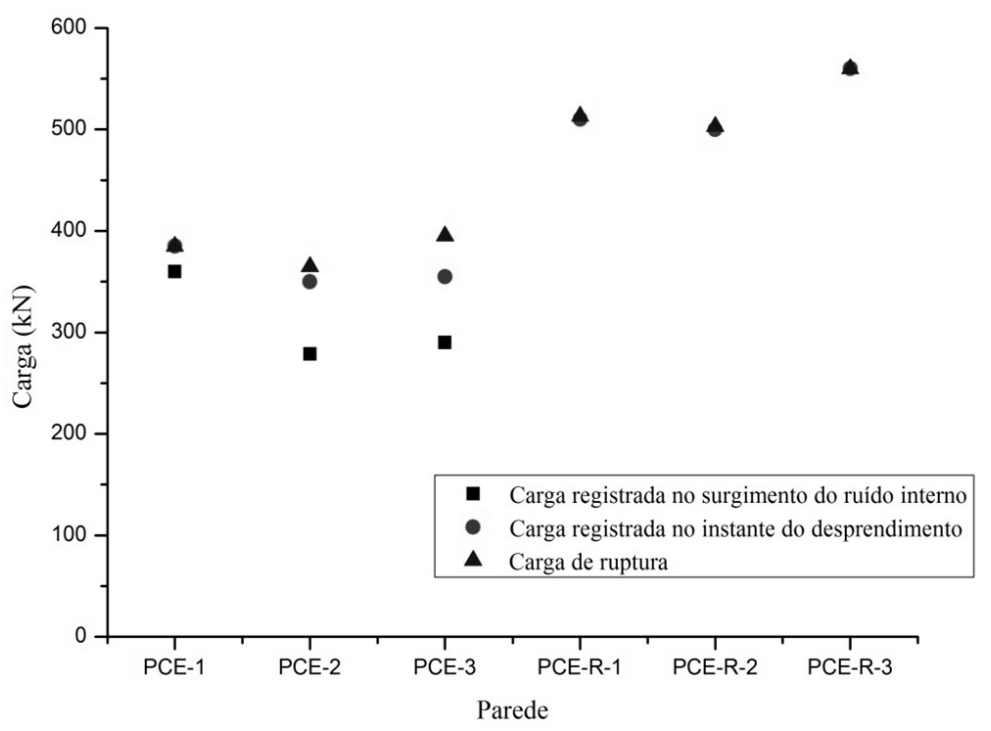

Nas paredes em que foi aplicado o emboço em uma das faces, não foi observado ao longo do carregamento nenhum indício de desprendimento do emboço em relação aos blocos, sendo que, visualmente, essa ligação permaneceu íntegra até a ruptura do sistema.

Na Figura 10, nota-se que a deformação foi maior para o caso onde as paredes não receberam o emboço antes da aplicação dos revestimentos cerâmicos; já para as paredes com o emboço, os valores de deformação foram praticamente iguais durante o evento observado de desprendimento e ruptura da estrutura.

A Figura 11 mostra a ocorrência dos desprendimentos das placas cerâmicas e da argamassa colante nestas paredes sem emboço.

Na Figura 12, verifica-se que a ocorrência dos desprendimentos das placas cerâmicas e da argamassa colante foi menor devido à aplicação do emboço.

Na Figura 13, é possível visualizar a região das paredes onde houve o desprendimento do emboço, argamassa colante e placa cerâmica, simultaneamente.

Como todas as paredes foram ensaiadas até a ruptura, pôde-se observar o comportamento do desprendimento do revestimento cerâmico, que foi caracterizado por:

(a) nas paredes cerâmicas sem emboço, o desprendimento do revestimento se deu a uma carga média de $363 \mathrm{kN}$, que corresponde a aproximadamente $95 \%$ da carga média de ruptura das mesmas; (b) nas paredes cerâmicas com emboço, o desprendimento do revestimento se deu a uma carga praticamente idêntica à carga de ruptura das mesmas, o que possibilita afirmar que na realidade não houve o descolamento do revestimento, mas sim a ruptura de todo o sistema; e

(c) neste sistema com emboço, pode-se considerar que não houve a ruptura do revestimento cerâmico, o mesmo se manteve inalterado praticamente até o momento da ruptura das paredes. Percebeu-se uma forte ligação entre emboço e alvenaria, pois terminado o ensaio, a camada de emboço permanecia em grande parte íntegra e aderida aos blocos, havendo o desprendimento somente da placa cerâmica em relação ao emboço.

\section{Conclusões}

De um modo geral, o presente trabalho mostra que em todas as paredes notou-se uma boa aderência da argamassa colante com os blocos e que no transcorrer de todos os ensaios, não foram observadas a presença de fissuras no revestimento cerâmico, nem mesmo para carregamentos próximos das cargas de ruptura.

Com base nos ensaios realizados, pode-se afirmar que, para alvenarias executadas com blocos cerâmicos e materiais semelhantes aos aqui estudados com as cargas aplicadas de forma concêntrica, não há previsão de ocorrência de danos até níveis de carregamentos abaixo do limite máximo de resistência das paredes. No sistema com emboço, nenhum indicativo de dano ao revestimento foi observado até a carga de ruptura. 
Figura 10 - Deformações de desprendimento do revestimento e de ruptura das paredes

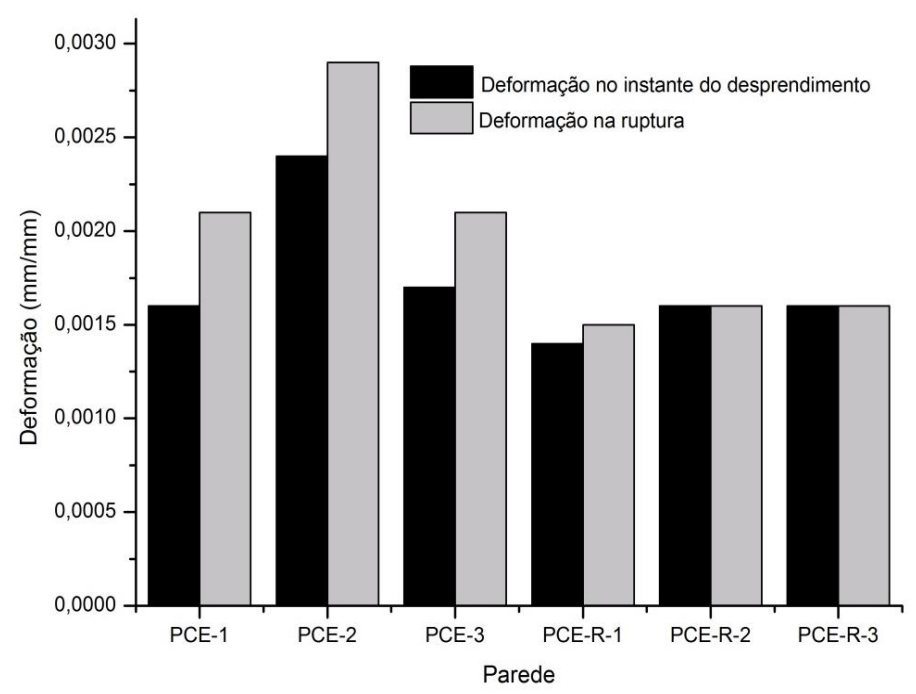

Figura 11 - Paredes cerâmicas sem emboço: descolamento do revestimento

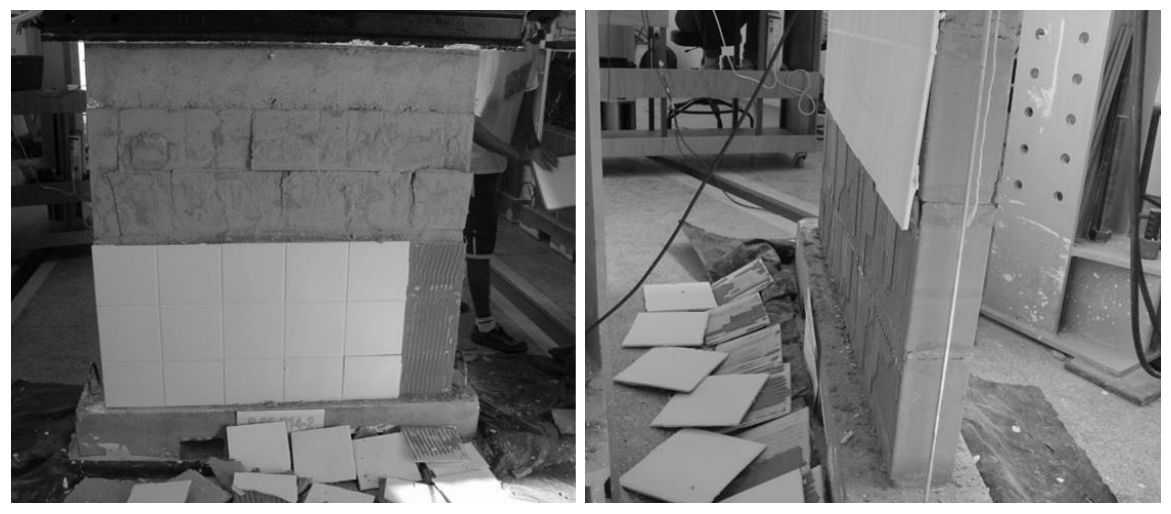

Figura 12 - Paredes cerâmicas com emboço: interface emboço/alvenaria

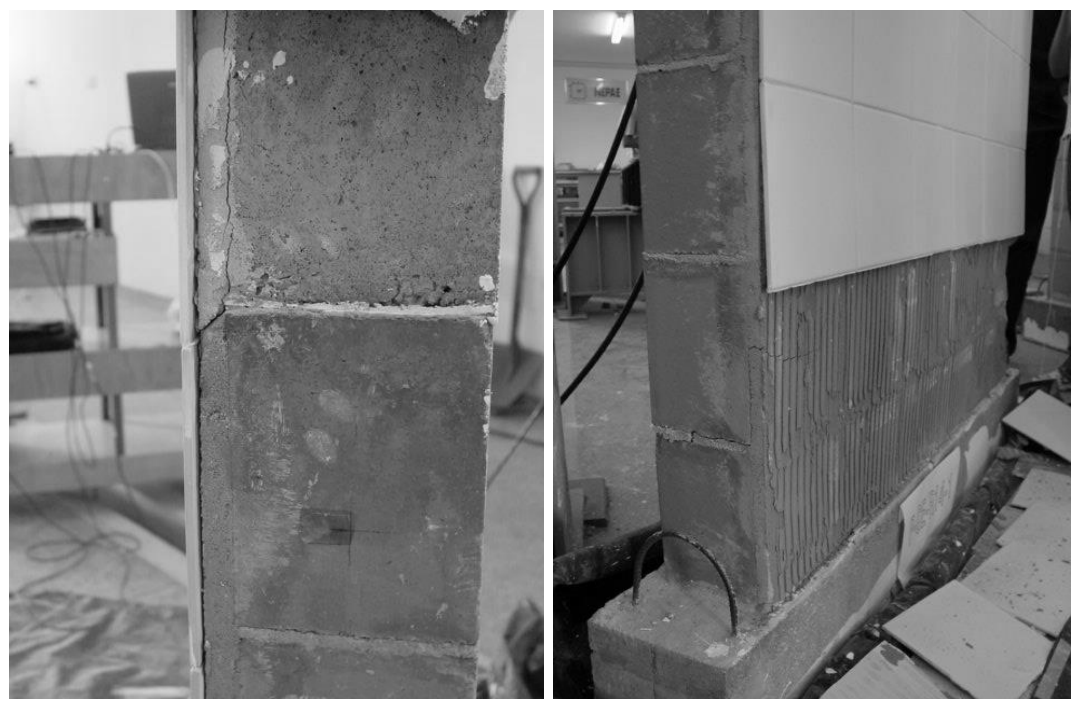


Figura 13 - Paredes cerâmicas com emboço: desprendimento do revestimento e emboço

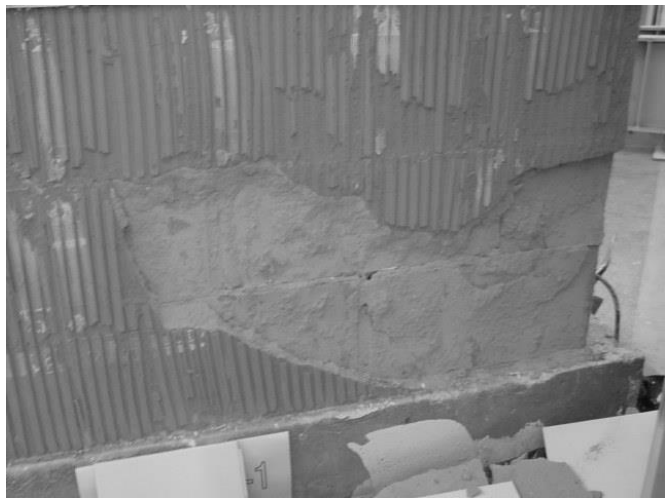

Portanto, é razoável admitir que os problemas patológicos ocorram para carregamentos muito próximos da ruptura onde, nas faixas de utilização da edificação, os carregamentos correspondentes não apresentam sinais de problemas patológicos no revestimento cerâmico se fixado sobre uma camada de emboço ou diretamente sobre os blocos de alvenaria.

\section{Referências}

ASSOCIAÇÃO BRASILEIRA DE NORMA TECNICAS. NBR 8949: paredes de alvenaria estrutural: ensaio à compressão simples. Rio de Janeiro, 1985.

ASSOCIAÇÃO BRASILEIRA DE NORMA TECNICAS. NBR 13749: revestimento de paredes e tetos de argamassas inorgânicas: especificação. Rio de Janeiro, 2013.

\section{ASSOCIAÇÃO BRASILEIRA DE NORMA} TECNICAS. NBR 13755: revestimento de paredes externas e fachadas com placas cerâmicas e com utilização de argamassa colante: procedimento. Rio de Janeiro, 1996.

\section{ASSOCIAÇÃO BRASILEIRA DE NORMA TECNICAS. NBR 15270-1: componentes cerâmicos: parte 1: blocos cerâmicos para alvenaria de vedação: terminologia e requisitos. Rio de Janeiro, 2005a.}

\section{ASSOCIAÇÃO BRASILEIRA DE NORMA}

TECNICAS. NBR 15270-2: componentes cerâmicos: parte 2: blocos cerâmicos para alvenaria estrutural: terminologia e requisitos. Rio de Janeiro, 2005b.

\section{ASSOCIAÇÃO BRASILEIRA DE NORMA} TECNICAS. NBR 15270-3: componentes cerâmicos: parte 3: blocos cerâmicos para alvenaria estrutural e de vedação: método de ensaio. Rio de Janeiro, 2005c.

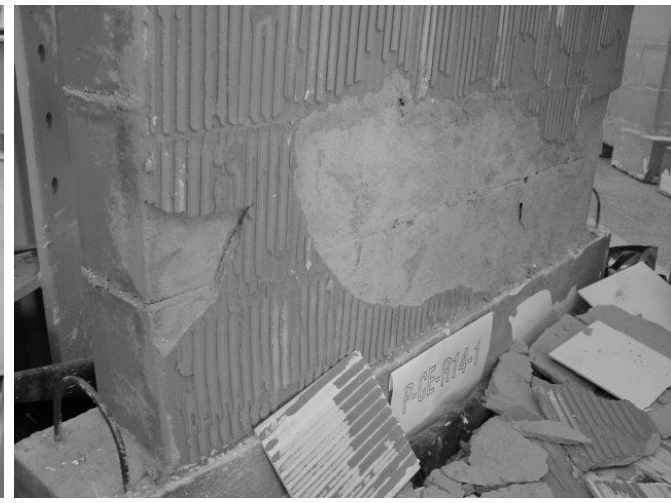

ASSOCIAÇÃO BRASILEIRA DE NORMA TECNICAS. NBR 14081-1: argamassa colante industrializada para assentamento de placas cerâmicas: parte 1: requisitos. Rio de Janeiro, 2012.

\section{ASSOCIAÇÃO BRASILEIRA DE NORMA}

TECNICAS. NBR 15812-2: alvenaria estrutural: blocos cerâmicos: parte 2: execução e controle de obras. Rio de Janeiro, 2010.

\section{BORTOLUZZO, C. W. Contribuição ao Estudo} do Comportamento Mecânico dos Revestimentos de Argamassa. São Carlos, 2000. 190f. Dissertação (Mestrado em Engenharia Civil)- Escola de Engenharia, Universidade de São Paulo, São Carlos, 2000.

BOSCHI, A. O. Uma Análise Critica do Setor de Revestimentos Cerâmicos. Revista Cerâmica Industrial, São Paulo, v. 7, n. 1/2, p. 8-13, mar./abr. 2002.

BOWMAN, R. Striving to Overcome Recurrent Challenges. In: WORLD CONGRESS ON CERAMIC TILE QUALITY, Castellon, 2008. Proceedings... Castellon, 2008.

CARDOSO, F. F. et al. Relatório Final do Projeto Capacitação e Certificação Profissional na Construção Civil e Mecanismos de Mobilização da Demanda: relatório final da etapa 1, proposta de estratégia. São Carlos: Escola de Engenharia, Universidade de São Paulo, 2007.

CAVALHEIRO, O. P.; MULLHER, L. E. Influência do Revestimento na Resistência de Pequenas Paredes de Blocos Cerâmicos Comuns. In: JORNADAS SUL-AMERICANAS DE ENGENHARIA ESTRUTURAL, 25., Porto Alegre, 1991. Anais... Porto Alegre: UFRGS, 1991. 
COLLANTES, C.M. Contribuição ao Estudo das Técnicas de Preparo da Base no Desempenho dos Revestimentos de Argamassa. São Paulo, 1998. 198f. Tese (Doutorado em Engenharia Civil) - Escola Politécnica,a Universidade de São Paulo, São Paulo, 1998.

FERES, J. P. L. Estudo da Argamassa de Rejuntamento: analise critica da norma NBR14992/2003 A.R. Argamassa a base de cimento Portland para rejuntamento de placas cerâmicas requisitos e métodos de ensaios. São Carlos, 2004. 114 f. Dissertação (Mestrado em Engenharia Civil) - Escola Engenharia, Universidade de São Paulo, São Carlos, 2004.

JUNGINGER, M. A Nova NBR 13755. In: ENCONTRO NACIONAL DE TECNOLOGIA DO AMBIENTE CONSTRUÍDO, 15., Maceió, 2014. Anais... Maceió: ANTAC, 2014.

\section{LIMA, L. C. Elaboração de Um Software Para} Especificação de Sistema Revestimento Cerâmico. São Carlos, 2003. 76 f. Tese (Doutorado em Engenharia Civil) - Escola de Engenharia, Universidade de São Paulo, São Carlos, 2003.

MEDEIROS, J. S.; SABBATINI, F. H. Tecnologia e Projeto de Revestimentos Cerâmicos de Fachadas de Edifícios. Boletim Técnico da Escola Politécnica da USP, Departamento de Engenharia e Construção Civil, BT/PCC/246. EDUSP, 28 p. São Paulo, 1999.
RIBEIRO, F. A. Especificação de Juntas de Movimentação em Revestimentos Cerâmicos de Fachadas de Edifícios: levantamento do estado da arte. São Carlos, 2006. 158 f. Dissertação (Mestrado em engenharia Civil) - Escola Engenharia, Universidade de São Paulo, São Carlos, 2006.

ROMANO, R. C. O. et al. Efeito do Procedimento de Mistura nas Características de Argamassas de Revestimento Industrializada. In: CONGRESSO PORTUGUÊS DE ARGAMASSAS DE CONSTRUÇÃO, 3., Lisboa, 2010. Anais... Lisboa: APFAC, 2010.

SABBATINI, F. H.; BARROS, M. M. S. B. Recomendações Para a Produção de Revestimentos Cerâmicos Para Paredes de Vedação em Alvenaria. Escola Politécnica da USP, PCC. R6-07/90 - Convênio EPUSP/ENCOL CPQDCC - EPUSP). São Paulo, 1990.

SICHIERI, E. P.; LIMA, L. C. Desenvolvimento e Qualidade dos Revestimentos Cerâmicos. In: ENCONTRO NACIONAL DE TECNOLOGIA DO AMBIENTE CONSTRUÍDO, 7., Florianópolis, 1998. Anais... Florianópolis: ANTAC, 1998.

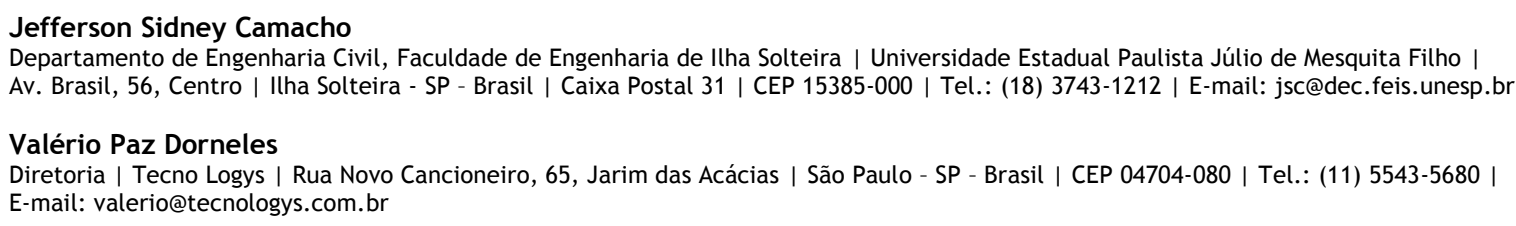

Alexsandro dos Santos Felipe

Departamento de Engenharia Civil | Universidade Estadual Paulista Júlio de Mesquita Filho | E-mail: alexunesp@yahoo.com.br

Revista Ambiente Construído

Associação Nacional de Tecnologia do Ambiente Construído

Av. Osvaldo Aranha, $99-3^{\circ}$ andar, Centro

Porto Alegre - RS - Brasil

CEP 90035-190

Telefone: +55 (51) 3308-4084

Fax: +55 (51) 3308-4054

www.seer.ufrgs.br/ambienteconstruido

E-mail: ambienteconstruido@ufrgs.br 